\title{
Regional Convergence in Greece (1995-2005): A Dynamic Panel Perspective
}

\author{
Mike Tsionas, Stylianos Sakkas, and Nikolaos C. Baltas \\ Department of Economics, Athens University of Economics and Business, 76 Patission Street, 10434 Athens, Greece \\ Correspondence should be addressed to Nikolaos C. Baltas; baltas@aueb.gr
}

Received 4 February 2014; Revised 21 May 2014; Accepted 22 May 2014; Published 25 June 2014

Academic Editor: Laura Gardini

Copyright (C) 2014 Mike Tsionas et al. This is an open access article distributed under the Creative Commons Attribution License, which permits unrestricted use, distribution, and reproduction in any medium, provided the original work is properly cited.

\begin{abstract}
This paper discusses the issue of regional convergence in Greece during the period 1995-2005. Following the theoretical concept of Barro and Salla-i-Martin, 1990 ( $\beta$ - and $\sigma$-convergence concepts), several tests are conducted to test for conditional or unconditional convergence across Greek regions including GMM estimation of Barro regressions. The results indicate absence of convergence across NUTS II regions while there is evidence of convergence at prefectural level (NUTS III). The effect of agriculture industry and services sector is examined and services are found to have significant impact on growth and convergence. Finally, we examine the effect of the implementation of the European funding programs in some detail.
\end{abstract}

\section{Introduction}

Growth is the key to economic welfare. Several studies and models (neoclassical and endogenous growth models), such as Solow [1], Barro [2-4], and Romer [5], show the importance of economic growth in all aspects of social life. But economic growth is closely related to convergence. In recent years, a new school, the New Economic Geography, was developed and has contributed to the convergence/ divergence discussion. Krugman [6] was the first to contribute to this field of study. In the past few decades, empirical and theoretical research on the subject of convergence produced a number of interesting results but often contradicting each other. In addition, economic policy across countries is often based on how fast economies are converging. For example, one of the main aims of the European Union policy is the European integration, that is, convergence within EUs ranks. Therefore the introduction of EURO as the common currency and the foundation of several EU institutions and bodies such as The European Committe Cohesion Fund and The European Regional Development Fund show EU's willingness for convergence among its member states.

The purpose of the paper falls squarely within this objective. More specifically, we use GMM techniques to estimate the rate of convergence at the NUTS II and III regional levels in Greece. Our basic model involves estimating a dynamic panel data with fixed effects, time effects, and possibly other covariates and represents a clear advance in terms of the method used in terms of econometric estimation of convergence rates.

This paper is organized as follows. In Section 2, we summarize the existing empirical evidence. Our main empirical findings are presented in Section 3. The final section presents conclusions and policy implications.

\section{Summary of Existing Empirical Evidence}

Empirical examination of convergence of European regions has been an intense area of study, partly because the EU policies place great emphasis on cohesion. For a summary of findings, the reader is directed to Alexiadis et al. [7], Basile and Usai, forthcoming; Button and Pentecost [8], Ertur and Le Gallo, [9], Magrini [10], Roberts and Setterfield, [11], Tondl [12], Tsionas [13], among others.

For Greece in particular, Tsionas [14] focused on convergence in Greek NUTS III prefectures for the period 19711993. The $\beta$-concept indicated convergence rate of $2 \%$ for the subperiod 1971-1981 and 4\% for the subperiod 19821993. Tsionas, following Quah's method $[15,16]$, concluded that polarization and economic dualism exist in Greek regions 
but there is also some evidence of structural change in the regional distribution of income. The bimodality of limiting distributions clearly shows the absence of convergence.

Alexiadis et al. [7] analyse club convergence for Greek prefectures during the period 1980-2005. His empirical model suggests that adoption of technology and diversity in a region's economic structure are crucial parameters in determining a club convergence pattern. In another study, Tsionas and Christopoulos [17] examined regional convergence within Greek prefectures during 1971-1995. They found that Greek prefectures have a tendency to converge to their steady states at the annual rate of $8.8 \%(-0.0879)$ at $1 \%$ significance level. In Siriopoulos and Asteriou [18] the convergence hypothesis is rejected. There is no convergence across Greek regions since estimates of $\beta$ are always positive and statistically insignificant. Economic dualism between northern and southern Greece exists while southern regions are converging with themselves and not with other regions.

Petrakos and Saratsis [19] used the same method as Siriopoulos and Asteriou [18], during the period 1981-1991 (using the NUTS III classification) arriving at different results. There is a tendency for convergence in the late 1980s. The secondary sector, EU integration, and quality of human capital are factors that affect regional convergence. This contradiction was obtained probably as the result of using regional instead of prefectural data.

The proper use of panel data could contribute significantly to the understanding of the process of convergence in Greece. Since no study has employed the techniques of dynamic panel data and GMM estimation, it is worthwhile to use this econometric framework in order to draw hopefully better and more robust evidence on convergence. As shown in Bernard and Durlauf [20], convergence can be embedded easily in the standard time-series context of analysis. Of course this embedding uses panel data (data for different regions over time) and employs dynamic regression. It is well known (see [21]) that LS is inconsistent when applied to dynamic panel data because of the nonorthogonality between the dynamic term (the lagged dependent variable) and the error term. A consistent estimator has been proposed by Arellano and Bond [22] and is used in the present study.

\section{Empirical Analysis}

3.1. Kernel Density Estimators and $\sigma$-Convergence. In this section we begin our empirical analysis for Greek regions at NUTS II level and we provide also some evidence for NUTS III. Kernel density estimators and $\sigma$-convergence are the measures used. We work with cross-sectional data for 13 Greek regions and 51 prefectures during 1995-2005. First, we focus on $\sigma$-convergence.

Apparently, absence of $\sigma$-convergence is almost certain (Figures 1 and 2). From 1999 onwards there is an obvious increase in the dispersion of GDP. Standard deviation rises from 0.22 to 0.30 . This outcome is somewhat surprising in view of the incoming funds from the EU. On the other hand, one could claim that these amounts were not distributed in the way they should. During 1999-2004, there was enormous

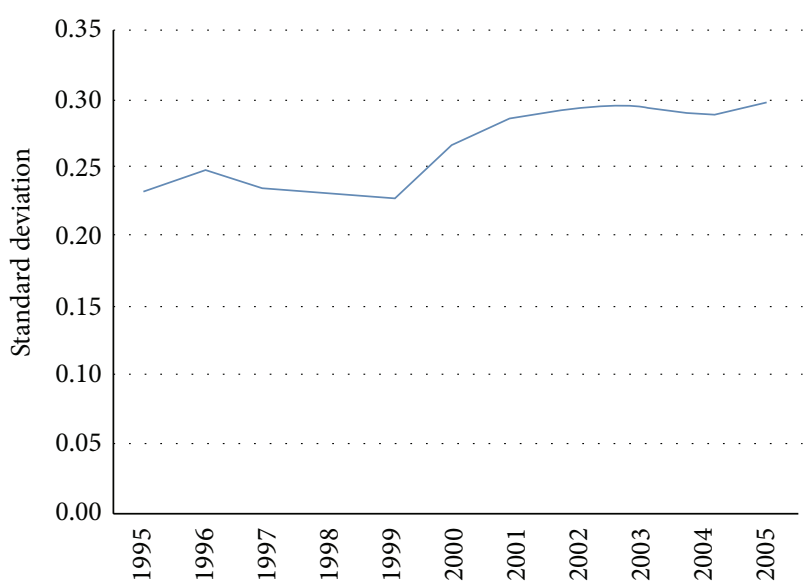

FIGURE 1: $\sigma$-Convergence, NUTS III.

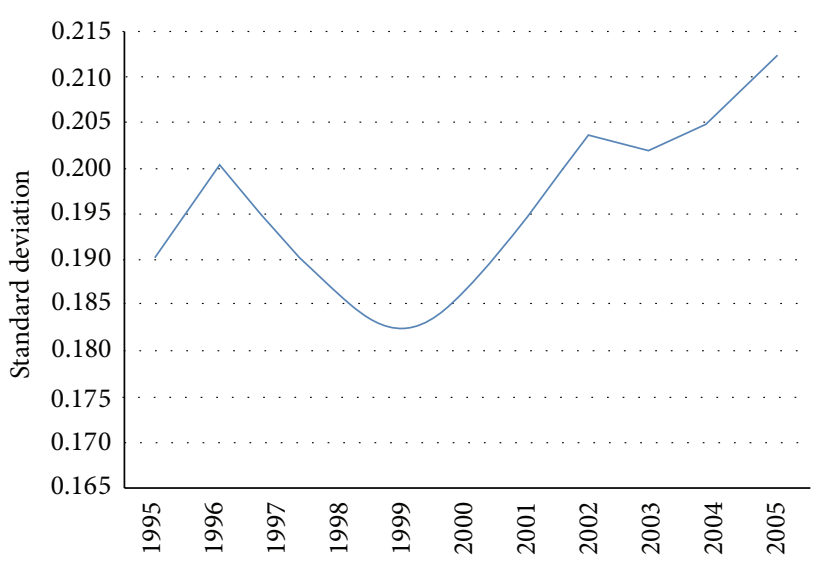

FIGURE 2: $\sigma$-Convergence, NUTS II.

spending for public infrastructure, in view of the preparation of the Olympic Games 2004. Attiki prefecture was the main receiver of EU funds.

We employ Kernel methods with automatically chosen bandwidth in order to estimate per capita GDP densities for NUTS II and III administrative levels during the period 19952005. (As a referee carefully pointed out, the shape of the univariate kernel density of per capita GDP may change from a bimodal to a unimodal one over time, without any convergence process. To assess convergence one has to analyze the intradistribution dynamics (using "conditional" density estimators), rather than the simple marginal univariate density (see Basile [23]). However, the problem is that kernel regressions for dynamic panel data are not a well-developed area in applied econometrics although they should. Therefore, we are obliged to leave this task for future research.) To obtain our dataset for kernel density estimators, we divide the initial per capita income series with the cross-sectional income average in order to remove the tendency from aggregate shocks. The results are based on the initial year (1995) and last year (2005) of our sample.

For NUTS III in 1995 we have a unimodal distribution (almost) with the dominant peak at 0.90 of the national per 


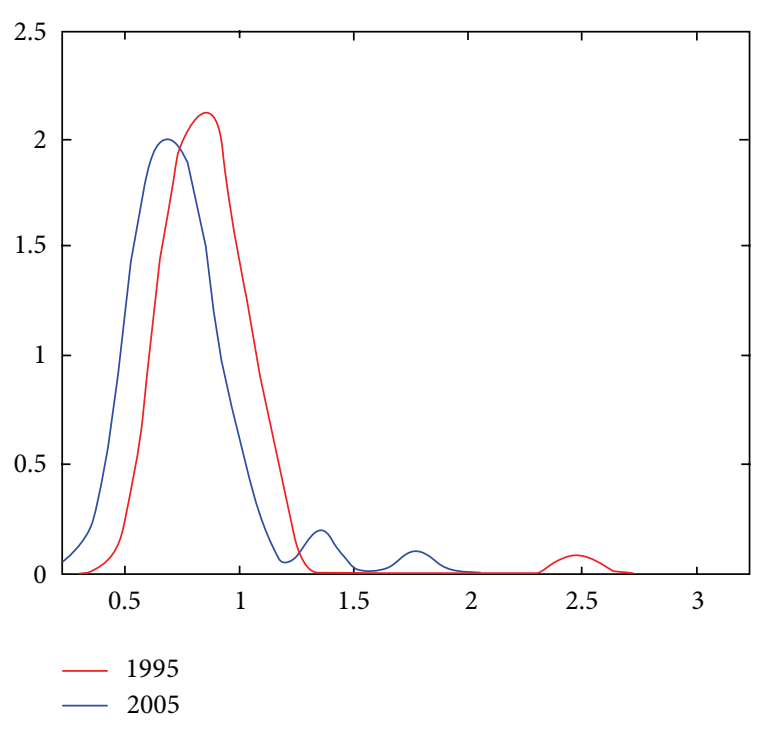

FIgURE 3: Kernel density estimators, NUTS III.

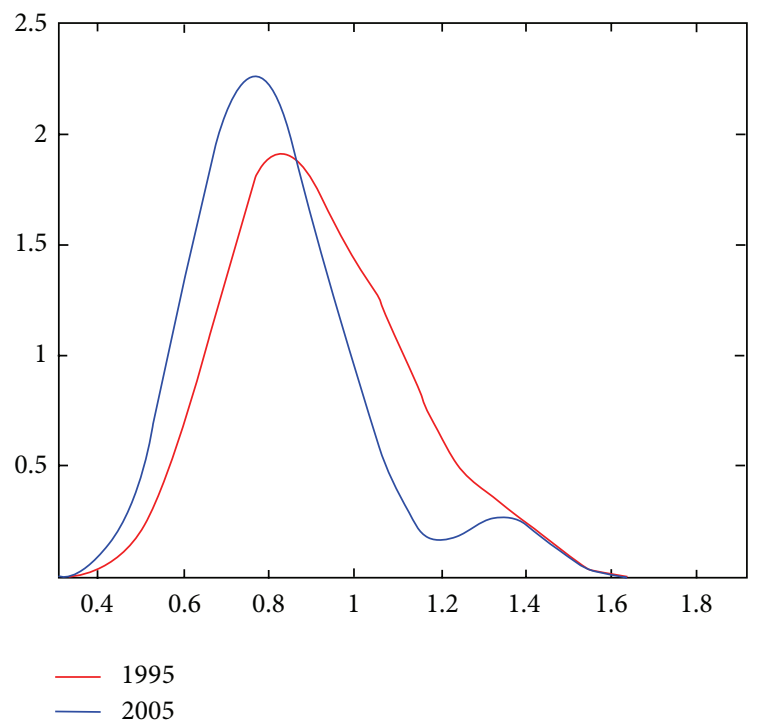

FIGURE 4: Kernel density estimators, NUTS II.

capita GDP average (Figure 3). We can also see a minor peak on the far right tail, We can also see a minor peak on the far right tail, which indicates a club of richer-than the averageprefectures. Ten years later, in 2005, there is a little change in the distribution. There is a tendency for multimodality of the distribution. The first peak is at 0.70 of the national average. There are also two other shorter peaks at 1.4 and 1.7 of the national average. However, the distance between the peaks (modes) in 1995 and 2005 decreased. So, the picture is mixed. For the NUTS II classification, it is clear that in 1995 we have a unimodal distribution (Figure 4). The majority of Greek regions are concentrated around $80 \%$ of the national average. In 2005, the distribution tends to be bimodal, for the major part. The first peak is at 0.85 of the national average, but there is also a cluster of regions, that is, a minor peak.
3.2. Cross-Sectional Analysis and $\beta$-Convergence. The classical cross-sectional analysis for testing $\beta$-convergence as proposed by Barro and Sala-i-Martin [24] depends on the following equation:

$$
\frac{1}{T} \cdot \log \left(\frac{y_{i T}}{y_{i 0}}\right)=a-\left[\frac{\left(1-e^{-\beta T}\right)}{T}\right] \cdot \log \left(y_{i 0}\right)+u_{i 0, T},
$$

where $i$ denotes the region, $t$ denotes time, $u \sim\left(0, \sigma^{2}\right)$ is the error term, and $\beta$ is the coefficient that shows the speed of convergence. If $\beta>0$, then convergence is implied. For simplicity we can transform the above regression (1) in the following way:

$$
\gamma_{i 0, T}=a-b \cdot \ln \left(y_{i 0}\right)+u_{i 0, T}
$$

where $\gamma$ denotes the growth rate of log per capita income and $b=\left(1-e^{-\beta T}\right) / T$. We can easily, of course, back out the speed of convergence $(\beta)$.

We performed a test, following Sala-i-Martin [25, 26], to investigate the existence of economic dualism in Greece between northern and southern regions by including a dummy variable taking the value of 0 for northern regions and the value of 1 for southern regions. It would be of great interest to include in our regression measures of human capital or technology and check their effect in economic growth and convergence as Romer [5] proposed. Unfortunately, data of this kind were not available for Greek regions. The regression is

$$
\gamma_{i 0, T}=a-b \cdot \ln \left(y_{i 0}\right)+N S \cdot X+u_{i 0, T} .
$$

The inclusion of the north-south dummy variable resulted (The estimation results are omitted but are available on request.) in a convergence speed, $\beta=1.2 \%(b=0.011)$ for NUTS II and NUTS III. At a glance it seems that there is convergence between southern and northern regions and elimination of economic dualism. Moreover, none of the coefficients at both administrative levels is statistically significant since $P$ value $>a \%(\alpha=1 \%, 5 \%, 10 \%$ significance level $)$. Therefore, convergence hypothesis is still rejected.

We also tested for conditional convergence. We use the share of services sector (ser) in total GDP (following the idea of Tsionas and Christopoulos, [17]) as the variable that serves as proxy for the steady state. We use indicators (gross value added) of agriculture, industry, and services sector because they have big impact on the formation of regional GDP considering the fact that agriculture and secondary sector are two major GDP contributors of regions like Thessalia, Dytiki Makedonia, Anatoliki Makedonia, Thraki, and Ipeiros, while services sectors contribute the most in touristic and business activity regions like Attiki, Notio Aigaio, Kriti, and Ionia Nisia. As Tsionas and Christopoulos [17] suggest, convergence in the services sector is the main reason for overall convergence in Greece. In addition to this, a large percentage of EU's structural funds during our sample period were given for investments in agriculture and fishery, improvement of services sector, and touristic infrastructure all over Greek region. 
TABLE 1: LS with structural variables-NUTS II.

\begin{tabular}{lccc}
\hline Estimates & Regression results & \multicolumn{2}{c}{$t$-statistic and $P$ value } \\
\hline$a$ & $0.14(0.15)$ & 0.94 & 0.37 \\
$b$ & $0.021(0.016)$ & 1.29 & 0.33 \\
agr & $0.000016(0.004)$ & 0.004 & 0.99 \\
ind & $0.00005(0.003)$ & 0.014 & 0.98 \\
Ser & $0.010^{* *}(0.003)$ & 3.24 & 0.012 \\
$R$-squared & 0.59 & \multicolumn{2}{c}{-} \\
Adjusted $R$-squared & 0.39 & \multicolumn{2}{c}{-} \\
\hline
\end{tabular}

Numbers in parentheses is the standard deviation. Single asterisk $\left(^{*}\right)$ : significance at $1 \%$, Double asterisk $\left({ }^{* *}\right)$ : significance at $5 \%$.

From these results, it is clear that, at both NUTS II and III levels, services sector is the driving force for growth and convergence since it is always positive and statistically significant and serves as proxy for the steady state. Table 1 indicates absence of convergence at NUTS II (The result is robust to both NUTS II and NUTS III classifications. It is also robust in a model that includes only services.)

3.3. GMM/Dynamic Panel Data Estimation. We extend our analysis and make use of panel data techniques to study the convergence hypothesis. In fact, we now employ pooled data so that we have more observations than the model with averaged data. We consider the generalized method of moments (GMM) estimator. Most previous studies have used cross-sectional models to perform inferences on convergence. However, convergence can be formulated and tested in a time-series manner [20] using panel data, that is, by utilizing the totality of the sample. For robust and efficient inference, the use of panel data is indispensable. In a dynamic context, it is well known that dynamic models based on panel data cannot be estimated by LS since the estimates are biased and inconsistent so we must resort to the Arellano and Bond [22] estimator to yield consistent estimators of the speed of the convergence and the contribution of covariates, if any, on growth (The estimator uses fixed effects for the regions. The effects are naturally independent of the errors. For more details and a summary see Arellano and Honore [21].)

The results obtained from dynamic panel data and GMM of the simple convergence hypothesis (not reported) confirm once again the absence of $\beta$-convergence in Greek regions and agree with those of Siriopoulos and Asteriou [18] for the nonconvergence hypothesis. The estimates are statistically insignificant for NUTS II regions but significant for NUTS III prefectures.

As we stated before, Greek convergence policy is structured mostly around EU's funding policy for member states (Community Support Frameworks (The CSF1 and CSF2 generally speaking were in favor of less developed regions. The priorities of CSF3 aimed to improve the competitiveness and the rise of employment. Investment of the CSF3 was focused on natural, human, and knowledge capital which might contribute to the increase of productivity.)) During our sample period, Greece was the receiver of two funding packages (CSF2:1994-99, CSF3:2000-06). To investigate the
TABLE 2: GMM estimation-NUTS II.

(a)

\begin{tabular}{lccc}
\hline Estimates & Regression results & \multicolumn{2}{c}{$t$-stat and $P$ value } \\
\hline Constant & $-0.103(0.09)$ & -1.13 & 0.25 \\
ln gdp $(\mathrm{t}-1)$ & $0.015(0.01)$ & 1.51 & 0.13 \\
CSF2 & $0.011^{*}(0.004)$ & 2.95 & 0.003 \\
CSF3 & - & & - \\
$R$-squared & 0.064 & \multicolumn{2}{c}{} \\
\hline
\end{tabular}

(b)

\begin{tabular}{lccc}
\hline Estimates & Regression results & \multicolumn{2}{c}{$t$-stat and $P$ value } \\
\hline Constant & $-0.036(0.09)$ & -0.39 & 0.69 \\
ln gdp $(\mathrm{t}-1)$ & $0.0085(0.01)$ & 0.85 & 0.39 \\
CSF2 & - & -0.78 & 0.43 \\
CSF3 & $-0.0031(0.003)$ & & \\
$R$-squared & 0.010 & & \\
\hline
\end{tabular}

Numbers in parentheses is the standard deviation. Single asterisk $\left({ }^{*}\right)$ : significance at $1 \%$, Double asterisk $\left({ }^{* *}\right)$ : significance at $5 \%$.

TABLE 3: GMM estimation-NUTS III.

(a)

\begin{tabular}{lccc}
\hline Estimates & Regression results & \multicolumn{2}{c}{$t$-stat and $P$ value } \\
\hline Constant & $-0.115(0.062)$ & -1.86 & 0.06 \\
$\ln$ gdp $(\mathrm{t}-1)$ & $0.016^{* *}(0.006)$ & 2.38 & 0.017 \\
CSF2 & $0.013^{*}(0.002)$ & 5.13 & 0 \\
CSF3 & - & & - \\
$R$-squared & 0.049 & & \\
\hline
\end{tabular}

(b)

\begin{tabular}{lccc}
\hline Estimates & Regression results & \multicolumn{2}{c}{$t$-stat and $P$ value } \\
\hline Constant & -0.036 & 0.59 & 0.55 \\
$\ln$ gdp $(\mathrm{t}-1)$ & 0.0084 & 1.24 & 0.21 \\
CSF2 & - & & - \\
CSF3 & -0.0035 & -1.31 & 0.28 \\
$R$-squared & 0.0064 & & \\
\hline
\end{tabular}

Numbers in parentheses is the standard deviation. Single asterisk $\left(^{*}\right)$ : significance at $1 \%$, Double asterisk $\left({ }^{* *}\right)$ : significance at $5 \%$.

effect of those two on growth and convergence, we estimate convergence equations including two time variables (CSF2, CSF3) with each one denoting the implementation period. Results are presented in Tables 2 and 3.

It seems (Service and nonservice components of GDP were not found to be statistically significant) that CSF2 has a positive effect on growth and convergence at both NUTS II and III regions and is statistically significant. On the other hand, CSF3 affects growth in a negative way. This finding agrees with the $\sigma$-convergence results. A careful look at $\sigma$ convergence results shows that after 1999 the standard deviation of per capita income increased. Therefore, the regional inequalities during the 3rd CSF implementation rise up (It should be attributed that most of EU funding was directed to Attica area where the Olympic Games mainly took place.) 
It should be noted that CFS3 was completed in 2009 and not 2005, and its impact will be fully assessed when data is available. But the most important finding is that the coefficient of $\log \mathrm{GDP}(t-1)$ is positive and insignificant implying absence of conditional convergence. Specifically, we have conditional persistence for NUTS II and conditional divergence for NUTS III.

As Benos and Karagiannis [27] notice, the contradicting results between different regions classifications may be due to the heterogeneity of per capita income among regions since different rich prefectures may belong to poor regions or the opposite. However, the difference here is between conditional persistence and conditional divergence. In both cases, convergence is absent. (This is the answer for referee's comment on the contradicting results between NUTS II and III.)

\section{Conclusions and Policy Implications}

In the European Union as a whole, it is known that regional disparities tend to dominate; see, for example, Magrini [10]. Therefore, a process of real convergence has not started yet, with the important policy implication that the monetary union may not be sustainable in the long run unless further measures are taken. The results in the present paper do not imply that European regional incomes tend towards convergence. What the results do imply is that regional differences in Greece are not so large so as to make the hypothesis of club formation appear plausible relative to the alternative of a unimodal limiting income distribution.

Although Greece shows tendencies towards convergence, this is not necessarily implying that these tendencies are strong enough to make Greek regions develop more relative to the European average. The same is, of course, the case with certain other regions of the European south; otherwise, we would not observe club formation at the lowest bottom of the European regional income distribution; see, for example, Magrini [10]. Therefore, it is clear that the issue of club formation and divergence at the European level is a much wider issue that has to be dealt with using common policies and a variety of financial and qualitative means.

For the examination of regional convergence in Greece, we used the classical analysis of Barro and Sala-i-Martin of $\beta$ - and $\sigma$-convergence. A robust finding from $\beta$-regressions is the absence of convergence within Greek regions and prefectures during the period 1995-2005.

On the contrary, using GMM and dynamic panel data, we concluded that during 1995-2005 convergence did not take place in Greek prefectures. The 2nd Community Support Framework (1995-99) has a significant impact on growth. On the contrary, the 3rd Community Support Framework does not. This fact shows that regional policy measures in Greece were not effective and raise questions about the rational implementation of CSFs.

\section{Conflict of Interests}

The authors declare that there is no conflict of interests regarding the publication of this paper.

\section{References}

[1] R. M. Solow, "A contribution to the theory of economic growth," The Quarterly Journal of Economics, vol. 70, pp. 65-94, 1956.

[2] R. J. Barro, "Economic growth in a cross section of countries," Quarterly Journal of Economics, vol. 106, no. 2, pp. 407-443, 1991.

[3] R. J. Barro, “Convergence," Journal of Political Economy, vol. 100, pp. 223-251, 1992.

[4] R. J. Barro, Economic Growth, McGraw Hill, New York, NY, USA, 1995.

[5] P. M. Romer, "Endogenous technological change," The Journal of Political Economy, vol. 98, no. 5, pp. 71-102, 1990.

[6] P. Krugman, "Increasing returns and economic geography," The Journal of Political Economy, vol. 99, no. 3, pp. 483-499, 1991.

[7] S. Alexiadis, C. A. Ladias, and P. Antoneta, "Converging and diverging regions in the EU: implications for regional policy," Regional Science Inquiry, Hellenic Association of Regional Scientists, vol. 0, no. 2, pp. 55-70, 2010.

[8] K. Button and E. Pentecost, "Testing for convergence of the EU regional economies," Economic Inquiry, vol. 33, pp. 664-671, 1995.

[9] C. Ertur and J. Le Gallo, "Regional growth and convergence: heterogenous reaction versus interaction spatial econometric approaches," in Handbook Of Regional Growth and Development Theories, R. Capello and P. Nijkamp, Eds., chapter 19, pp. 374388, Edward Elgar, 2009.

[10] S. Magrini, "Regional (Di)Convergence," in Handbook of Regional and Urban Economics, J. V. Henderson and J. F. Thisse, Eds., North-Holland, Amsterdam, The Netherlands, 2004.

[11] M. Roberts and M. Setterfield, "Endogenous regional growth: a critical survey," in Handbook of Alternative Theories of Economic Growth, M. Setterfield, Ed., Edward Elgar, Cheltenham, UK, 2010.

[12] G. Tondl, "The changing pattern of regional convergence," Robert Schuman Centre (EUI), RSC No. 97/53.

[13] E. G. Tsionas, "Productivity Convergence in Europe," Eastern Economic Journal, vol. 26, no. 3, 2000.

[14] E. G. Tsionas, "Another look at regional convergence in Greece," Regional Studies, vol. 36, no. 6, pp. 603-609, 2002.

[15] D. Quah, "Galtons fallacy and tests of the convergence hypothesis," The Scandinavian Journal of Economics, vol. 95, no. 4, pp. 427-443, 1993.

[16] D. Quah, "Twin peaks: growth and convergence in models of distribution dynamics," The Economic Journal, vol. 106, no. 437, pp. 1045-1055, 1996.

[17] E. G. Tsionas and D. K. Christopoulos, "Convergence and regional productivity differences: evidence from Greek prefectures," The Annals of Regional Science, vol. 38, no. 3, pp. 387-396, 2004.

[18] C. Siriopoulos and D. Asteriou, "Testing the convergence hypothesis for Greece," Managerial and Decision Economics, vol. 18, no. 5, pp. 383-389, 1997.

[19] G. Petrakos and Y. Saratsis, "Regional inequalities in Greece," Papers in Regional Science, vol. 79, no. 1, pp. 57-74, 2000.

[20] A. B. Bernard and S. N. Durlauf, "Interpreting tests of the convergence hypothesis," Journal of Econometrics, vol. 71, no. 1-2, pp. 161-173, 1996.

[21] M. Arellano and B. Honore, "Panel data models: some recent developments," in Handbook of Econometrics, vol. 5, chapter 53, Elsevier, Amsterdam, The Netherlands, 2000. 
[22] M. Arellano and S. Bond, "Some tests of specification for panel data," Review of Economic Studies, vol. 58, no. 2, pp. 277-297, 1991.

[23] R. Basile, "Intra-distribution dynamics of regional per-capita income in Europe: evidence from alternative conditional density estimators," Statistica, vol. 70, pp. 3-22, 2010.

[24] R. J. Barro and X. Sala-i-Martin, "Convergence across states and regions," Brookings Papers on Economic Activity, vol. 1, no. 1, pp. 107-182, 1991.

[25] X. X. Sala-i-Martin, "The classical approach to convergence analysis," The Economic Journal, vol. 106, no. 437, pp. 1019-1036, 1996.

[26] X. X. Sala-I-Martin, "Regional cohesion: evidence and theories of regional growth and convergence," European Economic Review, vol. 40, no. 6, pp. 1325-1352, 1996.

[27] N. Benos and S. Karagiannis, Convergence and Economic Performance in Greece: New Evidence at Regional and Prefecture Level, Centre Of Planning and Economic Research, Athens, Greece, 2007. 

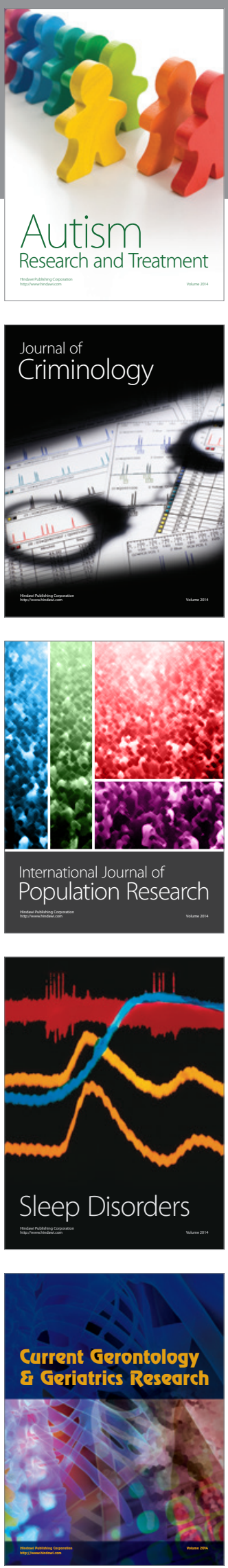
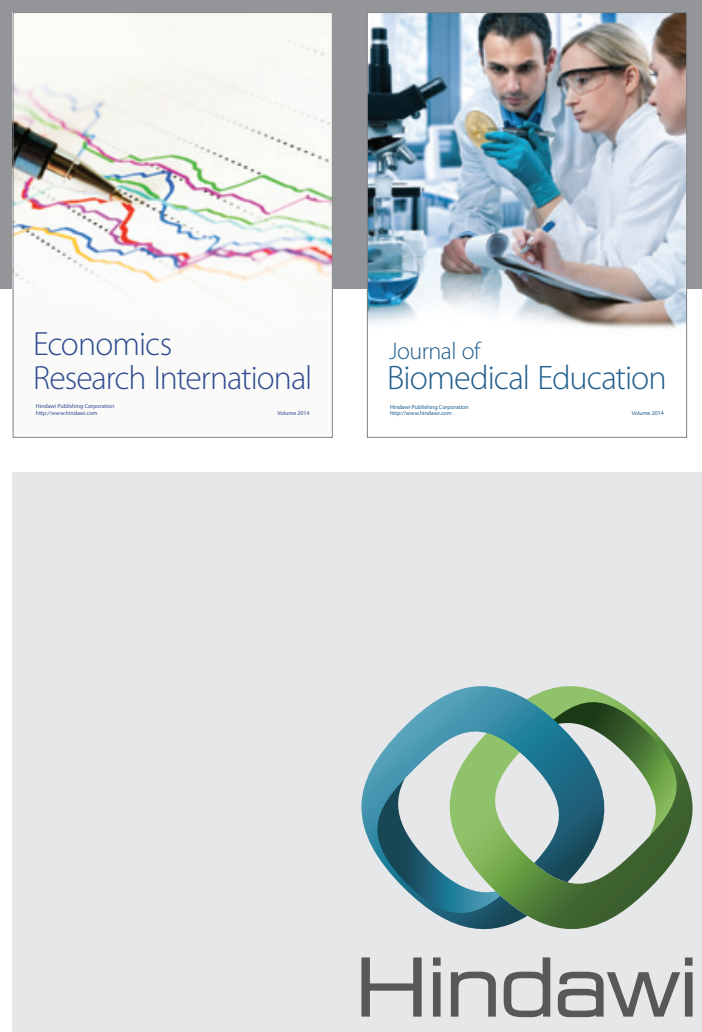

Submit your manuscripts at

http://www.hindawi.com
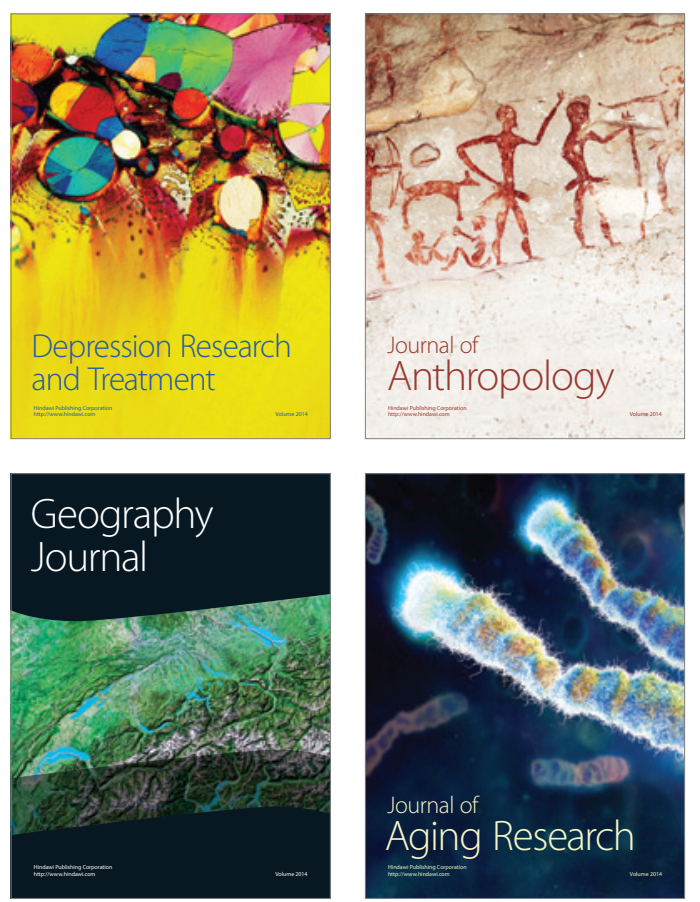
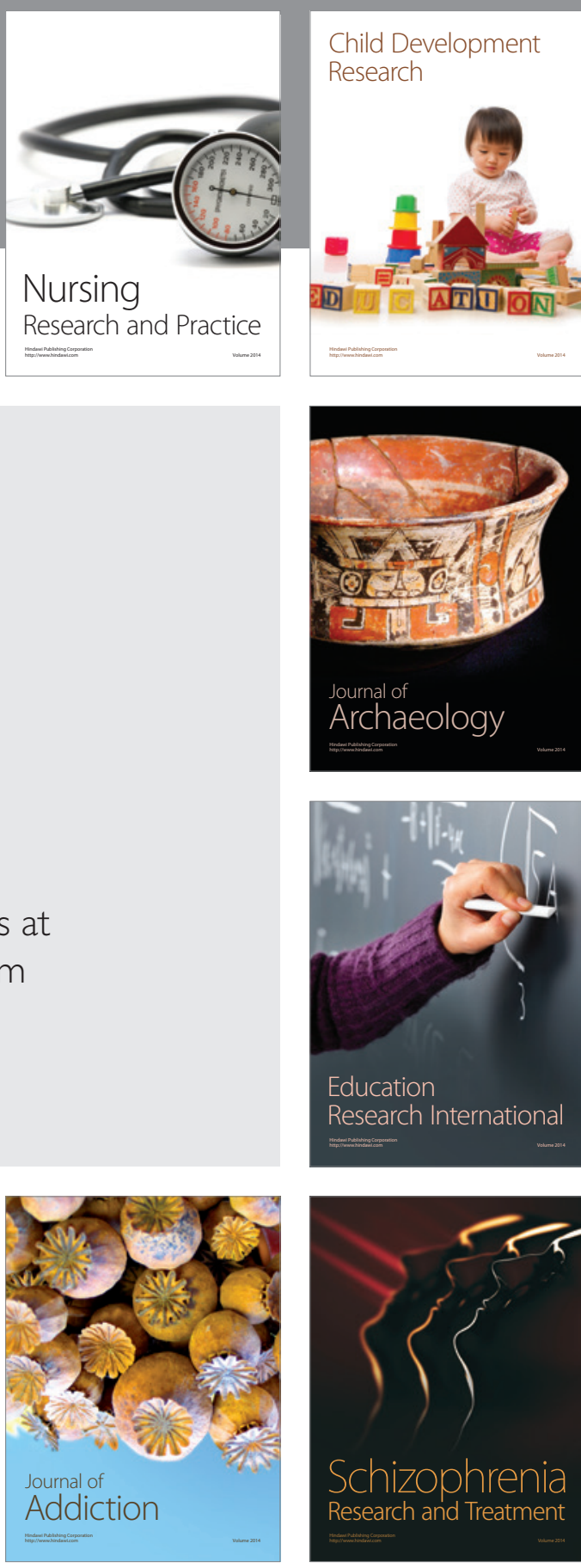

(D)
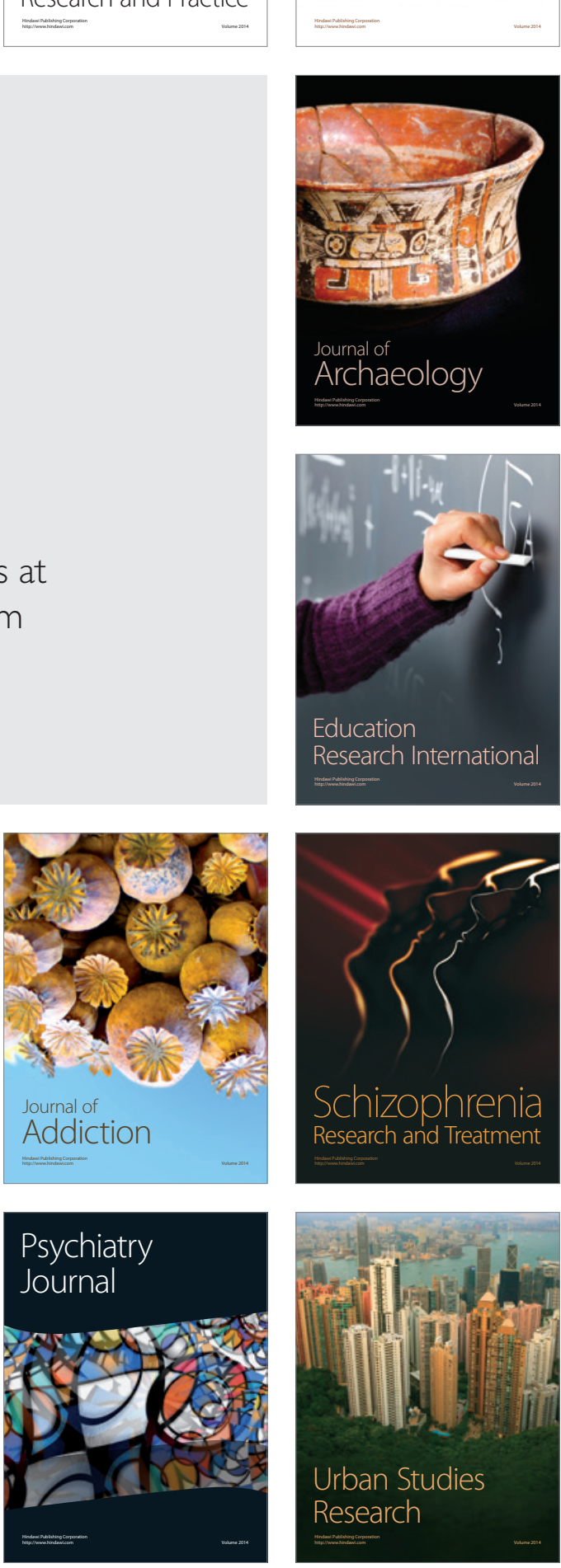